\title{
A NOTE ON SELF-TRANSLATION
}

\author{
JAN VANSINA \\ UNIVERSITY OF WISCONSIN-MADISON
}

Not so long ago this journal published an excellent overview of the issues related to the reliability of translations. ${ }^{1}$ But neither this, nor apparently any other study, considered the case of a text translated by its own author, hence a note on this topic may have some use. As I just finished translating of my own Le Rwanda ancien (Paris, 2001), I have been prompted to do so. ${ }^{2}$ The issues still are: how reliable is this sort of translation to the original? Is it really equivalent to the original?

Translations of modern works can be grouped in three categories according to the knowledge an author has about the language in which his or her work is being translated: the author does not know the language of the translation at all; the author knows that language well enough to check on the reliability of a translation; or the author knows that language to the point that he or she can translate the work himor herself. In the first case, even the author has no idea how faithful the translation is to the original. In the second case the overall reliability of the translation can be guaranteed by the author, but his or her limited knowledge of the language in question means that he or she may be unaware that some parts of the translation may not be faithful in the sense that readers might understand them in ways the author did not intend. Moreover, the great majority of translations by others will still strike native readers of the language into which it is translated as stilted because its rhetorical devices, and perhaps its syntax, do not wholly conform to the usual practice in that language. Indeed some passages may seem quaint or even especially striking merely because standard idioms or metaphors have been too literally translated. But surely self-translation should be completely reliable, especially when

${ }^{1}$ Beatrix Heintze, "Translations as Sources for African History," HA 11(1984), 13161.

History in Africa 31 (2004), 483-490 
the translated text has been also copy-edited by a native speaker of the language in which it is translated?

After all self-translation has the advantage over all others that the translator knows precisely what he or she intended to say as author, and is just as informed about the topics discussed as the author. Should that not offset the drawback that such translations usually are in breach of the general rule which states that translations should be created by a native speaker of the language into which the text is translated? The very fact that the author is competent enough in to write a translation acceptable to native speakers should be reassuring. Even so, I will argue that, while self-translations can be equivalent to the original, they can never be "the same thing" as the original.

Le Rwanda ancien was not translated word by word, but sentence by sentence and paragraph by paragraph. although in a few cases long periods, which are more common in written French than in English, have been divided into several sentences. In order to keep the translation as equivalent as possible to the original I decided, except for the correction of typographical errors, not to alter the text at all even in order to bring it up to date by inserting additional information (text, footnotes, bibliography, or arguments). In the end though I could not resist introducing a slight chronological correction based on new data for the years 1876-85, and mentioned this in a paragraph about the translation which was added to the preface. Overall, few major quandaries arose in the translation of single words and practically none in the transposition of French into English syntax. The main difficulties occurred in the treatment of idioms and images, rhetorical devices or other issues of style, and the treatment of allusions. We discuss these points in succession.

As is well known, French and English share the form of many words whose meanings are not identical. Routine issues are the avoidance of using false friends such as "mouton" (the animal) and "mutton" (its meat only), and the primacy of the context in deciding what the exact meaning is. Hence "la culture des ignames" is "yam cultivation" but "la culture du Kivu" is "Kivu culture." For another example-in a discussion about archeological ceramics, French "vase" is not English "vase" but the technical term "ware." The choice of one among several possible English words to render the meaning of the French original was sometimes less obvious. In general I chose the one most commonly used and so most familiar to the readers. Thus French "bovin" (used as a noun) referring to the ox family of ruminants is not rendered into 
English as "bovine" (used as a noun)-even though that would be perfectly correct according to the dictionaries-but as "bovid" (even though this is not normally used as a noun) because that is the most common usage today in works similar to the one translated here. Similarly French "végétal" is English "vegetable" and not "vegetal" since the latter is rare, especially in the United States, and apparently becoming obsolete. For similar reasons I have usually preferred unadorned words in English-which are often derived from old English-rather than their polysyllabic synonyms of Latin or French derivation. No doubt the latter often seem the obvious choice, but in fact their use is often less common than other terms and that can make them more difficult to understand. For example, French "pertinent" can be English "pertinent" or "relevant," but in most contexts the latter is used and it is perhaps better known, hence it has been preferred. One might be tempted to render "pertinent" as "apposite" but because French expresses that nuance by "approprié, convenable, juste, à propos" its use as a translation for "pertinent" is not warranted. ${ }^{3}$

A few French words raised major problems because no word with a sufficiently overlapping semantic field could be found in English. The most vexing problem was "bricolage" in the title of the last appendix "Bricolages prédynastiques." One dictionary translates"bricolage" as "pottering," "bricoler" as "to potter, to do odds and ends," "bricoleur" as "potterer, jack of all trades, shuffler," and "bricole," among others, as "a petty job." "Fitting odds and ends, fiddling with, juggling, tinkering" convey only a part of the meaning of "bricoler." In this book it specifically designates the process of reusing a collection of what had been different tales of fiction or "fairy tales" to cobble together a brand-new master narrative in which each tale acquired a new significance and was now deemed to be fact, not fiction. A complicated paraphrase could not be used to translate "bricolage" since the word forms part of a title and has to remain short. In the end I did not translate "bricolage" at all and the title became "Predynastic Fairy Tales." This choice does entail a loss of meaning, but as the following text makes the process designated by "bricolage" quite clear, there was no overwhelming need to translate the word itself. Of course in making such decisions it helps that the author is also the translator!

${ }^{2}$ Le Rwanda ancien was written in French and translated into English, which are not my native languages, but I have been using both of them on a daily basis for nearly half a century and I am familiar with technical literature on African history in both as well as in some of the major literary works in both languages.

${ }^{3}$ For these reasons bilingual dictionaries do not suffice as reference works for translators. One must also consult unabridged monolingual dictionaries. 
Standard idioms and routine images should never be translated literally but rendered by the use of an equivalent image or idiom. Thus "la goutte qui fait déborder le vase" (literally "the drop that made the vase overflow") becomes "the straw that broke the camel's back" and " tout se passe comme si ..." (literally "everything happens as if ...") becomes "one may think that," as this expression renders the intended meaning of the French idiom rather well. However, some cases can be rather tricky, especially when an image is encapsulated in a single word. Thus (p.160) "rayonnement" in "dès la fin du XVIIIe siècle le rayonnement du royaume ... affectait une vaste région" to indicate that the kingdom influenced some developments over a vast region is better not rendered as "irradiation" which reminds one of X-rays or isotopes, while "radiance, effulgence, radiation" are equally unsuitable. I did not come up with an equivalent image and therefore rendered its meaning directly in a pedestrian way: "By the end of the eighteenth century the policies and activities of the ... kingdom . . . affected a vast region..."

Because style is so intimately tied to a language, its literary usages, and the habits of its reading public, it is impossible to recreate it. Hence I strove to render the content and the meaning of each sentence as accurately as possible in translation and did not attempt to create an "equivalent" style in English. The style used in the original had deliberately eschewed flowery expressions and resonant periods in favor of a more condensed exposition by using shorter and often directly affirmative sentences and I attempted to be as pithy and succinct as possible. But I made no corresponding deliberate choice of style in English except for an attempt to keep the style as plain as possible and for the introduction of a slight tendency towards understatement. The styles of both versions are certainly not equivalent, because the English is simpler and less emphatic than the French. That matters because stylistic devices are used to convince readers and keep them interested, and the English and French versions will certainly affect their readers in different ways.

One particular rhetorical device is the division of chapters by subtitles. The usage in Le Rwanda ancien is rather standard for French books of this sort even though it is not so common in English works. Still, I maintained it in the translation because these subtitles allowed for abrupt changes of topic and because keeping them makes it easier to compare the translation with the original. Hence I run the risk that some English readers may be annoyed by these subtitles, which they may perceive as boring, pedantic, even condescending. The transformation of a slightly more dramatic or emphatic presentation in the French original into a more understated English version has been 
achieved to some extent by using more subdued adjectives or adverbs, but also by a deliberate decision not to follow the original where it used a cascade of successive rhetorical questions, to dramatize the following discussion. In most cases the translation was content to replace all, or all but the first of, such sets of questions by affirmative sentences.

Overall the initial and sometimes the concluding paragraphs of most chapters have been the most difficult to translate because artifices of style had been used more in these passages to capture the attention of the reader and to convey meaning in a more condensed fashion. For instance chapter 2 opens as follows:

French: "Le royaume nyiginya a été fondé par RUGANZU Ndori. Voilà une affirmation qui contredit tous les auteurs et la majorité des sources orales. Pourtant il en est bien ainsi ..."

English: " RUCANZU Ndori founded the Nyiginya kingdom. That statement contradicts all the authors and most of the oral traditions. And yet it is so..."

The content of both is nearly identical, yet the effect is not the same because in French there is an implied exclamation by the use of "Voilà," which is omitted in English. One might translate "Indeed, that is a statement which. ...", but that would still not render the implication of the French exclamation in which the "voilà" ("lo and behold"?) is paired to and stands in contrast to affirmation because that word evokes a speaker who is willing to stand by what he or she says, while "statement" is more neutral and colorless. Once again, in this case as in most others I strove to render the bare content and sacrifice some of the rhetoric in favor of a much plainer translation than the original.

Rather unusual for most translations from French into English, where the situation is usually the other way around, in this case the conciseness of the original French style has sometimes led me to add words to the translation in order to convey the full meaning of the original. For example "comme par le passé, le Burundi . . ." (p.198) becomes "once again, as in past times, Burundi ..." The "as"by itself without "the once again" would probably not be enough to convey the notion that the statement includes a referral to previous chapters.

The title of almost any book tends to be a rhetorical construct that embroiders a great deal of meaning in few words and very often relies on unstated associations or allusions. Hence the translation of titles is always fraught with danger. In this case the situation was actually even more tricky than usual. The original title had been $A u$ Rwanda ancien: le royaume nyiginya, with an unusual but not unknown inversion des- 
tined to attract readers who recognize "Rwanda" but not "nyiginya." The publisher then decided to replace the initial "Au"by "Le," which actually makes a significant difference, suggesting that the Nyiginya kingdom was equivalent to all of ancient Rwanda, whereas the whole book argues that the Nyiginya kingdom was only one among sever$\mathrm{a} /$ many societies found in ancient $\mathrm{R}$ wanda. Thus the title as published implies a position which the book as a whole strenuously opposes. Hence in the translation I reverted to the original title, The Nyiginya Kingdom in Ancient Rwanda, with the "in" and without the inversion in the hope of course that, although Rwanda is not the first word, it will still be noticed. But since English "ancient" usually refers to a very distant past, this title was not acceptable either. In the end and in order to avoid other undesirable connotations "Le Rwanda ancien" became "Antecedents to Modern Rwanda."

The literary device known as the allusion is a nightmare for translators because, since they are intended to be allusions, they never stand out in the text, which makes sense even without any knowledge of the allusion. By alluding, an author merely wishes to convey something over and beyond the text itself. Allusions usually only draw attention to parallels or comparisons and are often addressed only to a subset of the audience. A straightforward translation gives no more clues about them than the original does. A major example in Le Rwanda ancien is the beginning of chapter 1 (p. 23): "[1]e thêatre principal où se déroulera l'histoire du royaume nyiginya est le Rwanda central ..." translated as "[t]he main stage on which the Nyiginya kingdom emerged and where its history was played out is central Rwanda." 4 Nothing here signals an allusion. Yet the image of a stage is an allusion to the initial words "When the curtain is finally raised" used by Alexis Kagame in his Un Abrégé de l' etbno-histoire du Rwanda (Butare, 1972), 57, to open his chronicle of the deeds of the Nyiginya kings. The allusion is repeated in the first paragraph of appendix 2 (p. 269), that is, the last part of the book, and there it is made explicit both in the original and in the translation.

The allusion actually crops up first at the outset of the first chapter to contrast an opening gambit that sets the stage with a genuine society rather than a spurious king, as in Kagame's chronicle. It is repeated at the end of the book-the occasion which denies Kagame's most authoritative account the most-to drive that point home. Many Rwandans are assiduous readers of Kagame's works, and for them the allusion and its implications are obvious. Still, most others will miss it, whether they read the original or the translation. Thus in this case the allusion

${ }^{4}$ Note the rearrangement of the sentence in English. 
was intended for only a subset of all readers and a subset which reads French. Hence nothing essential is missed even if the translation did not stress this allusion

A fairly straightforward example of a more difficult problem in this book is the two-level allusion which occurs in the last sentence of chapter 9 (p. 246). "Plutôt Rwabugiri: roi maudit" is translated as "Rather Rwabugiri: a king accursed." The first level of the allusion is easy and explained in note 240 in the original and in translation. Accursed alludes to both Shongoka's curse and that of Mazimpaka's wives in much earlier times. It is a tongue-in-cheek comment on the practice at the court of finding precedents for whatever situation needs to be explained. All of this is just as accessible in the translation as it is in the original, but the second level is not. The same accursed alludes to the well-known (in France) set of historical novels by Marcel Druon which interprets a long half-century of French royal history as if it was but the result of a curse made by the Knights Templar. Here the allusion implies a parallel between Rwabugiri and Philip IV, the French king who destroyed the order of the Templars. Both kings have been praised by some historians as powerful, centralizing figures, and castigated by others as the instigators of long-term disaster. This level of the allusion is probably lost on all English readers. Yet it is not essential to the understanding of the text to catch it and most readers would resent a footnote about it as unbearably patronizing and pedantic.

"Bricolages" in the title of the second appendix "Bricolages prédynastiques," which has just been discussed, was expressly chosen as a strong allusion to an argument by Lévi-Strauss. He used the word to label the process of creating mythical thought which he describes in his La pensêe sauvage (Paris, 1962), 26-47, and which is similar to the process by which Nyiginya historiologues cobbled an early dynastic history together. ${ }^{5}$ But as the latter process is described in the text of the appendix, it did not seem necessary to include a specific footnote referring to Lévi-Strauss' book. So once again something is lost, but something that was not essential to the argument of the book.

\section{III}

Self-translations may well be the most faithful of all possible translations since the author is responsible for both versions. They may well

\footnotetext{
${ }^{5}$ Actually this title of Lévi-Strauss is famous for its internal allusion. "Pensée" means "thought" but also "pansy" and the cover picture showed a pansy. Hence "untutored thought" stands to "trained thought" as a "wild pansy" stands to"domesticated plant." No translator of the book seems to have been able to render this title so as to maintain the allusion!
} 
convey the same basic information for which the book is read, but they are not in fact totally equivalent. The translation always conveys less information, if only because some of its allusions are lost, but perhaps even more so in that some of the information about style and wording by which to evaluate its author is also lost. Most readers of the translation may well associate its style and some of the linguistic expressions used with realms completely different from the ones the original evokes in most of its readers, and in the same way both groups of readers may also gain quite a different mental image of the author and his or her enthusiasm, biases, perspicacity, or blind spots. So, however close a translation might be to an original, the two can never be fully equivalent. That means that whenever it is important for a reader to grasp exactly what is argued or asserted in a given passage recourse must be had to the original. Indeed as I realized after the completion of the translation I made, that observation is just as valid for the author. 